\title{
Extension Study on Electricity Market of Power Plant Investment Environment
}

\author{
Yuting Wang ${ }^{1}$, Kezhen Liu ${ }^{1}$, Chenkai Mo ${ }^{2}$ \\ ${ }^{1}$ Faculty of Power Engineering, Kunming University of Science and Technology, Kunming, Yunnan Province, China \\ ${ }^{2}$ Jiaxin Power Plant, Jiaxin, Zhejiang Province, China \\ Email: wangyuting1030@foxmail.com, liukzh@sina.com.cn
}

Received February, 2013

\begin{abstract}
When the global electricity industry has reorganized the structure and introduced competitive market mechanism world widely, China is no exception. Since 2002, "Electricity System Reform Program” was enacted. The mode of the State Power Corporation was divided. It means China's electricity market steps into the mode of Wholesale Competition. The meaning of the evaluation of power plant investment decision is to provide references for the market members when they made the decisions through the comprehensive evaluation of internal performance of Power Plant and the external investment environment, therefore further optimizing the allocation of funds, avoiding the risks, pursuing maximize of the profits.
\end{abstract}

Keywords: Power Plant Investment Environment; Evaluation Index System; Extension Evaluation

\section{Introduction}

Since China's first construction of power lines in 1882, China has gradually become one of the largest power systems in the world [1]. Closely related to the development of China's electric power industry and the reform of the electricity system, the government's over interference in enterprises and highly unified planning economic system from the beginning of the liberation to reform and open up the separation of government administration from enterprise management and self-exploration of the market-oriented operating system and then gradually try to plant network separate competitive bidding market. China's electric power system reform has gone through a tortuous and long road. From the separation of plant and grid, power plant investment project always has been the focus of the electric power investment research because as its large investment and long construction cycle since 2002. Therefore, investment environment evaluation can make investment decision more scientific, standardized and programming before the power project investment, thus reducing the maximum degree of the risk from the policy [2,3].

\section{China's Power Market Characteristics Analysis}

Since the enactment of promulgated The Power System Reform Plan from 2002, our country's electric power market gradually began to change to Wholesale Compe- tition mode [4-7]. In this mode, all power generation companies and transmission network is no longer a vertically integrated operation monopoly power company must be in the vertical split its affiliated power generation companies to pull away from the grid in removing all independent into a self-financing independent power producers. At the same time, establish a relatively sound basis the separation of plant and grid the electricity market, power generation companies in this electricity market bidding. Wholesale competition model is shown in Figure 1.

At present, China's power market is moving towards

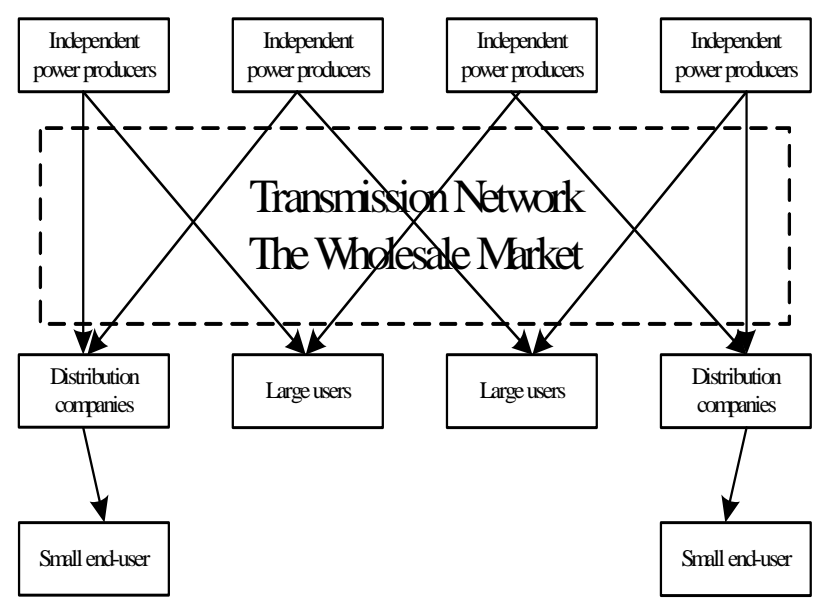

Figure 1. Wholesale competition model. 
wholesale competition mode, only the power suppliers to participate in the competition in which the identity of the third party. However, in order to achieve the maximization of profits within the electricity market, improve production efficiency, perfect competition is necessary. So before plant construction, power plant investment environment evaluation help power plant to save their own competitive torrents gains.

\section{Constructing an Extension Evaluation Model}

Extension assessment method [8-10] is the extension theory applied to evaluation of things, establishing multiindicators evaluation model parameters, and quantifying the quality of the evaluation results. It can reflect the actual features to be evaluated the comprehensive features of things level integrally. In this paper, the extension assessment model is defined as follows:

Let $M$ represent matter-element $\mathrm{E}$ for the space of the basic power plant investment evaluation factors, $C$ is a set of evaluation factors $C=\left\{c_{1}, c_{2}, \cdots, c_{n}\right\}$, $\mathrm{n}$ is the number of evaluation factors. Will be invested in accordance with the characteristics of the power plant investment evaluation factors affect the number of levels of the factors are divided into several different levels, the establishment of a power plant investment evaluation level domain $U=\left\{u_{1}, u_{2}, \cdots, u_{m}\right\}, m$ is an investment evaluation.

\subsection{Determine the Classical Domain and Section Domain}

The Power plant investment evaluation of classical domain and joint domain respectively are $M_{0 j}$ and $M_{u}$.

$$
M_{0 j}=\left(N_{0 j}, C, V_{o j}\right)=\left[\begin{array}{ccc}
u_{j} & c_{1} & V_{0 j 1} \\
& c_{2} & V_{0 j 2} \\
& \vdots & \vdots \\
& c_{k} & V_{0 j k} \\
\vdots & \vdots \\
& c_{n} & V_{0 j n}
\end{array}\right]
$$

$$
=\left[\begin{array}{ccc}
u_{j} & c_{1} & \left\langle a_{0 j 1}, b_{0 j 1}\right\rangle \\
& c_{2} & \left\langle a_{0 j 2}, b_{0 j 2}\right\rangle \\
\vdots & \vdots \\
c_{k} & \left\langle a_{0 j k}, b_{0 j k}\right\rangle \\
\vdots & \vdots \\
& c_{n} & \left\langle a_{0 j n}, b_{0 j n}\right\rangle
\end{array}\right]
$$

The above formula, $N_{0 j}$ represents the $\mathrm{j}$ investment grade, $j=1,2, \ldots, m ; C_{k}$ said the evaluation factors in the level of investment level, $k=1,2, \ldots, k, \ldots n ; V_{o j}$ is $u_{j}$ on the magnitude of the evaluation factors $C_{k}$ range, each power plant investment grades taken on its multi corresponding characteristic data range $\left\langle a_{0 j k}, b_{0 j k}\right\rangle$.

\subsection{Determine the Power Plant to be Evaluated Model}

Evaluation of Power plant investments $E$ the results of the actual data obtained or calculated using physical element $\mathrm{M}$ is expressed as follows:

$$
M=(E, C, V)=\left[\begin{array}{ccc}
E & c_{1} & V_{1} \\
& c_{2} & V_{2} \\
& \vdots & \vdots \\
& c_{n} & V_{n}
\end{array}\right]
$$

The above equation, $E$ is the power plant investment performance to be evaluated; the $c_{k}$ magnitude of the corresponding $V_{k}$ power plant is to be evaluated investment performance $E$.

Due to investment performance evaluation of seated structural upper factors is composed of a number of lower factors. The single factor at the low level may be composed by the lower layer of the multi-factor. If you want to evaluate the performance of a power plant investment, so the impact on the basis of the power plant performance factors stratified, low-level factors and comprehensive, the last factor of the high-level synthesis, and then was the investment performance of the plant level. Therefore, according to the characteristics of matter-element divergence, matter-element $M$ can be expanded to:

$$
\begin{array}{r}
M=(E, C, V)-\mid\left\{\left(E_{1}, C, V_{1}\right),\left(E_{2}, C, V_{2}\right), \cdots,\right. \\
\left.\left(E_{k}, C, V_{k}\right), \cdots,\left(E_{n}, C, V_{n}\right)\right\}
\end{array}
$$

constraint condition: $E=E_{1} \cup E_{2} \cdots \cup E_{k} \cup \cdots \cup E_{n}$

In the above formula: $\left\{E_{1}, E_{2}, \cdots, E_{k}, \cdots, E_{n}\right\}$ is investment evaluation factors subset for $E, n$ is investment evaluation sub divided set number.

For $M_{k}=\left(E_{k}, C, V_{k}\right)$ can be further expanded according to the actual situation, based on the contents of the previous modeling, the model only needs to expand to two layers . The bottom evaluation factors $E_{k p}$ is:

$$
M_{k p}=\left(E_{k p}, C, V_{k p}\right)=\left[\begin{array}{ccc}
E_{k p} & c_{1} & V_{k p 1} \\
& c_{2} & V_{k p 2} \\
& \vdots & \vdots \\
& c_{n} & V_{k p n}
\end{array}\right]
$$

\subsection{Determine the Evaluation Level Associated}

Let $x_{0}$ be an arbitrary point on the real axis $(-\infty,+\infty)$, $X_{0}=\langle a, b\rangle$ for any real number field interval, $\rho\left(x, X_{0}\right)$ to point $x_{0}$ to the interval distance, so: 


$$
\rho\left(x, X_{0}\right)=\left|x_{0}-\frac{a+b}{2}\right|-\frac{1}{2}(b-a)
$$

Away from the basis to establish the correlation function, the elementary correlation function can be expressed as:

$$
k(x)=\frac{\rho\left(x, X_{0}\right)}{\rho(x, X)-\rho\left(x, X_{0}\right)}
$$

To be evaluated investment performance factors $E_{k p}$ about levels associated can be expressed as:

$$
k_{j}\left(v_{k p i}\right)=\frac{\rho\left(v_{k p i}, V_{0 j i}\right)}{\rho\left(v_{k p i}, V_{U i}\right)-\rho\left(v_{k p i}, V_{0 j i}\right)}
$$

Let a be evaluated factors $C_{k}$ weight coefficient of $a_{i}$ and $\sum_{i}^{n} a_{i}=1$ is to be rated investment performance factors $E_{k p}$ association level $\mathrm{j}$ :

$$
k_{j}\left(E_{k p i}\right)=\sum_{i}^{n} a_{i} \bullet k\left(v_{k p i}\right)
$$

\subsection{Grading to be Evaluated Investment Performance $E_{k p}$}

If

$$
k_{j 0}=\max _{j_{0} \in\{1,2, \cdots, m\}} k_{j}\left(E_{k p}\right)
$$

then assess the performance of investment factors $E_{k p}$ belongs to level $j_{0}$.

\subsection{The Results of Evaluation of the Determined}

Transformation matrices by evaluating a performance investment subset $E_{i}$ extension comprehensive evaluation model, the comprehensive evaluation of the results of the evaluation factors set $E_{i}$.

$E_{i}$ Evaluation transform matrix obtained by the step (3) as:

$$
K_{i}=\left[\begin{array}{cccc}
k_{1}\left(E_{i 1}\right) & k_{2}\left(E_{i 1}\right) & \cdots & k_{m}\left(E_{i 1}\right) \\
k_{1}\left(E_{i 2}\right) & k_{2}\left(E_{i 2}\right) & \cdots & k_{2}\left(E_{i 2}\right) \\
\vdots & \vdots & \vdots & \vdots \\
k_{1}\left(E_{i n}\right) & k_{2}\left(E_{i n}\right) & \cdots & k_{2}\left(E_{i n}\right)
\end{array}\right]=\left(k_{p \times j}\right)_{n \times m}
$$

Assumptions subset of $E_{i}$, the weight of each factor $E_{i 1}, E_{i 2}, \cdots, E_{i n}$ is $A_{i}=\left(a_{i 1} a_{i 2}, \ldots, a_{i n}\right)$ respectively, to meet the $\sum^{n} a_{i}=1$, then the power plant investment performance evaluation model can create:

$$
\begin{aligned}
B_{i}=A_{i} \cdot K_{i}= & \left(a_{i 1} a_{i 2}, \ldots, a_{i n}\right) \\
& \cdot\left[\begin{array}{cccc}
k_{1}\left(E_{i 1}\right) & k_{2}\left(E_{i 1}\right) & \ldots & k_{m}\left(E_{i 1}\right) \\
k_{1}\left(E_{i 2}\right) & k_{2}\left(E_{i 2}\right) & \ldots & k_{2}\left(E_{i 2}\right) \\
\vdots & \vdots & \vdots & \vdots \\
k_{1}\left(E_{i n}\right) & k_{2}\left(E_{i n}\right) & \ldots & k_{2}\left(E_{i n}\right)
\end{array}\right]
\end{aligned}
$$

\subsection{Investment Grading}

If $b_{j 0}=\max \left\{B_{j}\right\}(12)$, and assesses the performance of $E$ is J level.

Repeat steps (3.1)-(3.6), you can come to the level of the final power plant investment environment $\mathrm{E}$ belongs.

\section{Determined the Weights Based on AHP}

Analytical Hierarchy Process is a combination of a quantitative and qualitative analysis of decision-making method. This method was applied to the power plant investment decisions evaluation of them. First, the investment decision-making to the complex issues broken down into a variety of factors, these factors attribute grouping has a different level, the same level factors as criteria, the next level of factors play a dominant role, at the same time by the previous constraints on the level factors. Topmost only one factor, namely the evaluation objectives, the middle level is a factor layer and the subfactors layer (index layer), the bottom of each factor is to be the evaluation the area object[11]. Hierarchical relationship of each factor is shown in Figure 2.

In judgment matrix is constructed based on the calculation of the relative weights of the factors under single criteria. Finally, the calculated weight value for consistency checking, when $C R=\frac{C I}{R I}<0.10$, indicating that the matrix having the consistency of the judgment can be accepted; or should re-adjust the judgment matrix until the consistency can be accepted.

\section{Example Analysis}

According to the exposition of the previous sections, the use of extension model is based on the actual investment of the power plant model structures [12].

The establishment of the evaluation factors $C=\left\{c_{1}, c_{2}, c_{3}, c_{4}\right\}$, which represent the possibility of capital appreciation, capital investment risks, the possibility of transfer of capital and power plant enterprises the ability to take risks in four areas.

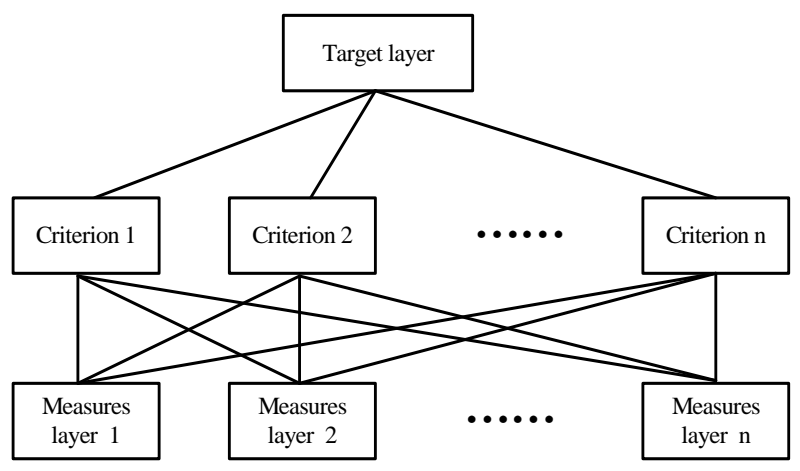

Figure 2. Hierarchy relationship of each factor. 
Assumed analysis, inspection this to establish the accuracy of the model selected Yunnan territory of a power plant operational data. Assuming a hydropower station in Yunnan province, the surrounding is rich in water resources. The main stream of water resources is in the Lancang river, Jinsha river the theoretical potential of 13 $730 \mathrm{MW}$, development and utilization of $8450 \mathrm{MW}$. The other tributary hydropower resources theory bears 2806 MW, development and utilization of $200 \mathrm{MW}$, been developed use 157.644 MW, there is considerable potential to be developed. Power station is $23 \mathrm{~km}$ away from the load area, and $700 \mathrm{~km}$ away from Kunming. Hydropower needs reservoir support the reservoir without inundated farming woodland, only submerged about 6 acres of dry land, 29.56 acres of shrub land (apart from a small amount of broad-leaved forest, are the bushes), and little damage to the surrounding environment. Power plant investment decisions evaluation and Extension levels are shown in Figure 3.

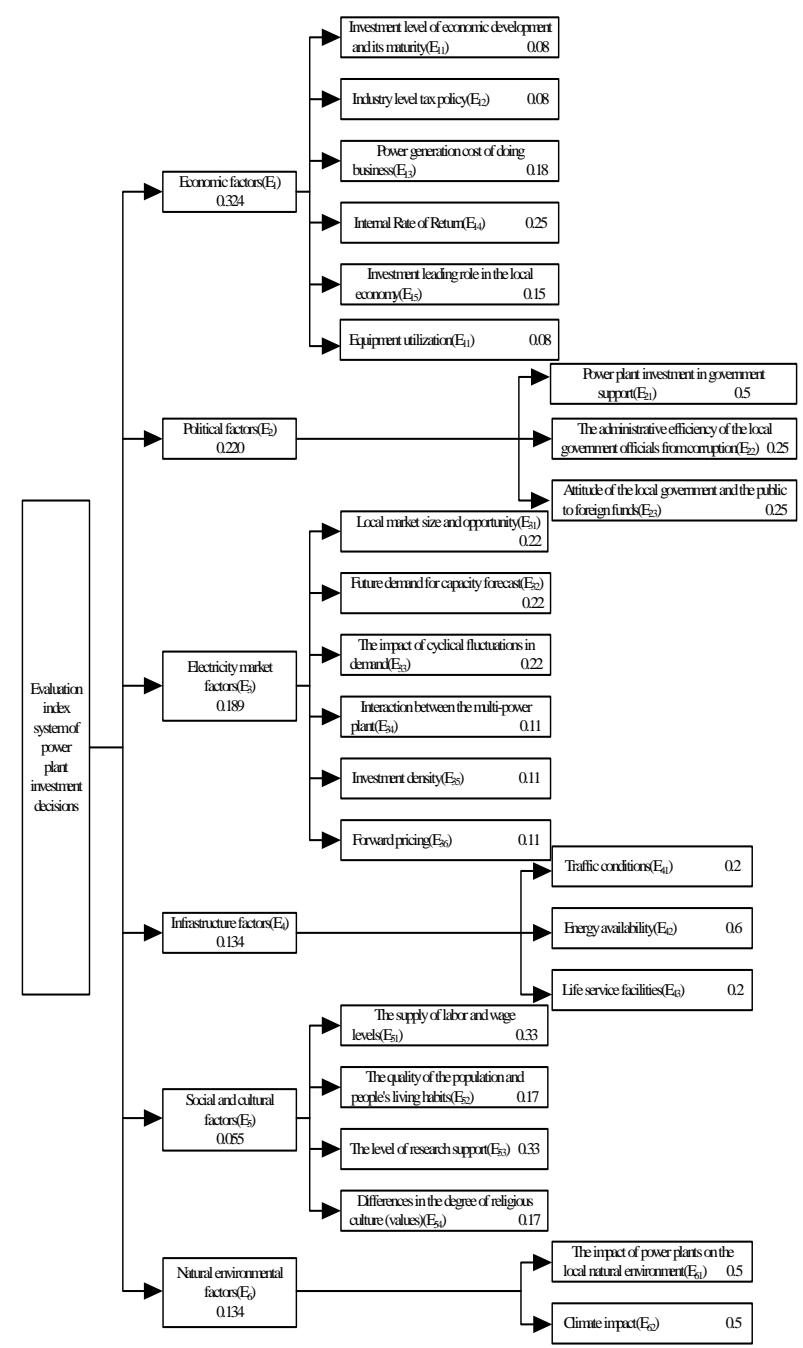

Figure 3. The identification of diagram about evaluation of power plant investment decision-making.
According to the initial power planning of Yunnan Electric Power Industry “11th Five-Year” Development Plan and the 2020 Vision of the Preliminary Studies, completed and put into operation in the year 2010, the surrounding four cascade hydropower stations installed capacity of up to $188 \mathrm{MW}$ four steps were: A power plant $15 \mathrm{MW}$, B power station expansion $48 \mathrm{MW}, \mathrm{C}$ power station $25 \mathrm{MW}$ and D power plant $100 \mathrm{MW}$. The maximum power load in 2010 will reach 102,000 kW in this state, existing power installed capacity of $92,000 \mathrm{~kW}$ only. Visibly the end load market demand is great and the surrounding power plant does not constitute competition. The units can achieve higher utilization hours.

According to the characteristics of the investment environment, investment environment is divided into five levels: A (8 to 10), A-(6 to 8), B (4 to 6), C (2 to 4), and $\mathrm{C}-(0$ to 2$)$. Value for the amount of matter-element, before Delphi method, confirmation of three experts in the different working environment, is shown in the following Table 1.

Table 1. The evaluation summary of the final decision power plant investment.

\begin{tabular}{|c|c|c|c|}
\hline Evaluation of projects & $\begin{array}{l}\text { Matter Element } \\
\text { for money }\end{array}$ & $\begin{array}{c}\text { Deviation } \\
\text { value }\end{array}$ & Rank \\
\hline Decision Overall rating & $\longrightarrow$ & -0.014 & A- \\
\hline E1 overall evaluation & $\longrightarrow$ & -0.0054 & A- \\
\hline - $\quad \mathrm{E}_{11}$ & $3.5,4,6,6$ & -0.041 & B \\
\hline E12 & $6,4,5,5$ & 0.125 & $\mathrm{~B}$ \\
\hline - $\quad$ E13 & $5,6,6,5$ & 0.125 & $\mathrm{~B}$ \\
\hline - $\quad$ E14 & $7,4,5,5$ & 0.0417 & B \\
\hline E15 & $8,7,7,6$ & 0.25 & A- \\
\hline - $\quad$ E16 & $8.5,7,6,8.5$ & 0.097 & A \\
\hline E2 overall evaluation & $\longrightarrow$ & 0.033 & A- \\
\hline - $\quad$ E21 & $8.5,4,5,6$ & -0.097 & A \\
\hline $\mathrm{E} 22$ & $8,4,7,3$ & 0.027 & A- \\
\hline - $\quad$ E23 & $7,4,5,6$ & 0.194 & A- \\
\hline E3 overall evaluation & $\longrightarrow$ & -0.076 & B \\
\hline - $\quad$ E31 & $8,3,6,4$ & -0.139 & A- \\
\hline E32 & $6,4,4,5$ & 0.041 & B \\
\hline E33 & $5,6,4,7$ & 0.042 & B \\
\hline E34 & $8,4,6,7$ & 0.027 & A- \\
\hline E35 & $8.5,4,5,4$ & -0.124 & B \\
\hline - $\quad$ E36 & $3.5,7,4,3.5$ & -0.104 & B \\
\hline E4 overall evaluation & $\longrightarrow$ & -0.224 & B \\
\hline - $\quad \mathrm{E} 41$ & $4,7,3,6$ & -0.083 & B \\
\hline E42 & $8.5,3,4,8$ & -0.104 & A \\
\hline - $\quad \mathrm{E} 43$ & $3.5,5,4,7$ & -0.041 & B \\
\hline E5 overall evaluation & $\longrightarrow$ & -0.208 & B \\
\hline - $\quad$ E51 & $8,4,6,8$ & -0.055 & A- \\
\hline E52 & $3,7,4,6$ & -0.083 & $\mathrm{C}$ \\
\hline E53 & $8,3,6,7$ & 0 & A- \\
\hline - $\quad$ E54 & $3,7,4,6$ & -0.083 & C- \\
\hline E6 overall evaluation & $\longrightarrow$ & -0.0625 & B \\
\hline - $\quad$ E61 & $4,6,4,6$ & 0 & B \\
\hline - $\quad$ E62 & $7,3,5,8$ & 0.027 & A- \\
\hline
\end{tabular}




\section{Conclusions}

This example assumes that the new hydropower station in Yunnan and the overall results of the evaluation as A-. As can be seen from the results of the analysis of the above table, planning the construction of the hydropower station is located in the more remote areas, so the infrastructure layer score is not too high. As far away from the political and commercial center of Yunnan, so the layer evaluation in the social and cultural factors is not too high. But the load point surrounding the power station construction behind, the entire electricity market is not in a state of competition, there will be no access to electricity system, but due to the limited level of social development, the end of the load demand in the next period of time will not significantly improve. From a market point of view, the construction of the power station's decision-making does not seem to.

The purpose of building one of the power station is able to play a part in driven investment of the construction of the power station in local economic development, which makes the construction of the plant has adequate social significance, so the relative evaluation results the results of the evaluation of the political and economic layer is relatively high. Promote local economic development at the same time, the income of the power station will promote but in the short term it can not be brought huge benefit for investors, but when the surrounding economic has sufficient development, the power plant gains will also have some improved. Although it may not be reflected in initial construction and operation stage, but after the loan repayment period power plant will gradually reflect its strong economic benefits.

Rich in water resources is another advantage of the power station construction in the building location. High water season accounted for most of the year. Also because the innate advantage, resulting save a lot of fuel cost. But operation of the power station need the support of the reservoir, power station at a disadvantage not only in construction investment and the construction period, but also to some extent in the construction of the reservoir damage to the surrounding environment, which is the reason of a low overall evaluation of the natural environment.

\section{REFERENCES}

[1] J. P. Liu. "China Power Industrial Policy and Industry Development," Beijing: China Electric Power Press, 2006.

[2] J. F. Shen, "China Power Industry Market Structure Analysis,” Modern Power, Vol. 21, No. 2, 2004, pp. 95-100.

[3] G. W. Han, J. J. Zheng and J. C. Lu, "Power Sustainable Development System Evaluation,” Power Technology Economy, Vol. 3, 2002, pp. 11-13.

[4] DOE, "American Clean Energy and Security act (ACES),”[EB-OL][2009-06], Available at: http://www.op engress.org/bill/111-h2454/show.

[5] FERC, "The Technical Conference of Integrating Renewable Resources into the Wholesale Electric Grid," [EB-OL][2009-04], Available at: http://www.ferc.gov.

[6] The UK, “Low Carbon Transition Plan,” The Department of Energy and Climate Change,UK, 2009.

[7] K. F. Zhou, D. X. Qin, S. M. Jiang. W. Wu and X. K. Yang, "Evaluation of the Mining Investment Environment about Four Neighboring Countries by Using Extension Method,” China Mining Magazine, 2010. 9.

[8] C. Y. Yang and W. Cai, "Extension Engineering Set," Beijing: Science Press, 2007.

[9] C. Y. Yang and Y. J. Zhang, “Extension Planning,” Beijing: Science Press, 2002.

[10] G. N. Liu, X. Q. Chen, G. Y. He and S. X. Zhou. "The Principle of the Evaluation Index System of Electricity Market and Build," Automation of Electric Power Systems Press, Vol. 29, No. 23, 2005, pp. 2-9.

[11] G. N. Liu, R. Q. Li, X. Q. Chen, G. Y. He and S. X. Zhou, "Electricity Market Regulatory Indicators and Market Rating System,” Automation of Electric Power Systems Press, Vol. 28, No. 9, 2004, pp. 16-22.

[12] J. S. Liu and M. Sun, "Power Generation Enterprise Core Competitiveness Evaluation System,” North China Electric Power University (Social Sciences), Vol. 1, 2006, pp. 54-58. 